\title{
Implementing Future Climate Change Scenarios Using a Stormwater Drainage Model for an Urban Catchment in Melbourne
}

\author{
$\underline{\text { S. Molavi }}^{\mathrm{a}}$, H. D. Tran ${ }^{\mathrm{b}}$ and N. Muttil ${ }^{\mathrm{a}}$ \\ ${ }^{a}$ College of Engineering and Science, Victoria University, PO Box 14428, Melbourne, VIC, 8001, Australia; \\ ${ }^{b}$ School of Civil, Environmental and Chemical Engineering, RMIT University, Australia \\ shahram.molavi@live.vu.edu.au
}

\begin{abstract}
One of the most important infrastructure in an urban area is its stormwater drainage system, which is used to convey the excess rainfall from the surface of the urban catchment to the natural watercourse. Conventionally, these structures are required to perform properly under the selected and generated events known as Design Rainfalls which have been statistically calculated using the recorded rainfall from the past. These events include the intensity and duration for the design rainfalls with different return periods or frequencies and are assumed to demonstrate the pattern and frequency of the previous rainfall events. This stationary assumption is currently questioned due to climate change. It is expected that high intensity rainfall events would be more severe and frequent. This in turn would lead to frequent flash floods as the urban stormwater drainage system would not be able to cope with the increased intensity of the storm events.
\end{abstract}

In Australia, the maintenance of the urban stormwater drainage system is the responsibility of local councils. With increase in rainfall intensities due to climate change, it is essential to assess the capability of existing drainage systems in handling these extreme events. With this aim, this research attempts to implement future scenarios of climate change for an urban catchment in Melbourne using a hydraulic model. The initial step in developing the hydraulic model included the extraction and correction of drainage system data from the GIS data available with the local council. The hydraulic model was calibrated and validated using captured flow data from the catchment.

Different scenarios for future climate change were developed and a scenario representing the future change is applied to the model and the results are presented in this paper. The results are expected to assess the capability of the drainage system to cope with the future climate change. The future scenario used design rainfalls of 6 hrs duration and return periods of 50 and 100 years, which were extracted from the IFD curves obtained from the Bureau of Meteorology web site. These design rainfalls were increased by factors of $10 \%$, $20 \%$ and $30 \%$ and the impacts of these increased rainfall events on the drainage system were assessed. The impacts were especially addressed using three important functional parameters of the drainage system under each scenario. These parameters were:

- Infiltration loss

- Surface runoff

- $\quad$ Final surface storage (Depression Storage)

It was observed that for the analysis using $6 \mathrm{hrs}$ duration design rainfall, a 30 percent increase in the rainfall intensity, for 50 years return period events, the maximum runoff change is $44.5 \%$ while the infiltration loss and final storage increased by $9.6 \%$ and $7 \%$ respectively. For the 100 years return period and increase in rainfall by $30 \%$, the three factors (of infiltration loss, surface runoff and final surface storage) increase by about $8.7 \%, 42.8 \%$ and $7.2 \%$ respectively. It is observed that the increase in the surface runoff is considerably higher than the increase in infiltration and storage capacity. Any further increase in the extreme events would contribute in more surface runoff accumulation.

Keywords: Hydraulic model, climate change, urban drainage systems, extreme rainfall events 
Molavi et al., Implementing future climate change scenarios using a stormwater drainage model for an urban catchment in Melbourne

\section{INTRODUCTION}

Climate change is expected to lead to an increase in intensity and frequency of extreme rainfall events (Mailhot et al., 2010). Semadeni-Davies et al. (2008) assessed the impacts of climate change and urbanization on drainage system at Helsingborg, Sweden. They showed that in severe conditions, the total runoff volume will increase by $24.7 \%$. Nie et al. (2009) conducted another case study on impact of climate change on urban drainage system for the period 2071-2100 in Norway and demonstrated that for an increase in precipitation of $20 \%$ above the present climate condition, the number of flooding manholes would increase by $43 \%$ and Combined Sewer Overflows would increase by $36 \%$.

Grum et al. (2006) evaluated the climate change on urban drainage for urban areas of Copenhagen in Denmark based on regional climate model simulations. The results revealed that extreme events would occur at least twice as often as they have been observed during the past decades. The Australian Bureau of Meteorology (2010) reported a $0.6^{\circ} \mathrm{C}$ increase in temperature across Australia since 1960. Based on the report, during the period 1900-2010, the overall rainfall has increased over Australia, while showing a substantial decrease over south of Victoria, southwest of Western Australia and southeast of Queensland. Globally, the annual projection (according to IPCC (2007)) shows an average increase of $1.8{ }^{\circ} \mathrm{C}$ to $4{ }^{\circ} \mathrm{C}$ until 2099. The global climate models indicate that global mean precipitation will increase with global warming, although there are substantial spatial and seasonal variations (IPCC 2007). Overall, in the current century, global precipitation over land is expected to increase by about $5 \%$, while precipitation over ocean is expected to increase by about $4 \%$ (IPCC 2007).

Urban drainage infrastructure is expected to handle flood designs based on the required level of serviceability and economic values (Arisz and Burrell, 2006). Change in return period of extreme rainfalls will affect the serviceability of drainage system. There is an increasing concern within the urban water authorities regarding how to cope with the future challenges of climate change before it becomes too late. The policy makers should establish their policies based on the most accurate scenarios and scientific and reliable evaluation tools. Hydraulic models have long been used for simulation of urban runoff. And without calibration and validation using field data, the scientific value and reliability of hydraulic models would be compromised.

This study aims to assess the impact of climate change on the drainage system for an urban catchment in Melbourne, Australia. The outcome of this study can help urban water authorities in planning to mitigate the flooding impacts of climate changes. In this study, a hydraulic model was built using SWMM 5 model and data from the case study area. The model was calibrated and validated using field data and checked against a variety of the future climate change scenarios generated from 6hrs duration design rainfall.

\section{CASE STUDY SITE}

The suburb of Springvale in the City of Greater Dandenong Council located in the east of Melbourne was selected as the case study site. The total area of the case study site is 2945 ha. This area consists of 17 urbanised sub-catchments (shown in Figure 1 (a)), with area ranging from 18 to 579 ha. The numbering in Figure 1 (a) represents the sub-catchments before development. For ease in referencing, this numbering is used in this study to address the hydraulic analysis for each sub-catchment. The schematization of the hydraulic parameters of the catchment such as pipes, pits and topography were available in the associated GIS files (obtained from the City of Greater Dandenong Council).

Due to the lack of flow data necessary for model calibration, a flowmeter was installed in July 2012. The area upstream of the flowmeter is henceforth called Calibration Area in this study because only the parameters of this area were calibrated using the available flow data. The Calibration Area (identified by the red circle in Figure 1 (a)) is located in north east of the case study is bounded from the north by a railway line. Based on field investigations, all the runoff produced from the Calibration Area is conveyed through only one existing $600 \mathrm{~mm}$ outlet pipe. The flowmeter is installed at the bottom of this $600 \mathrm{~mm}$ pipe to capture runoff from the Calibration Area, which would be used for calibrating the hydraulic model.

As far as rainfall data from the case study site is concerned, the Bureau of Meteorology station at Springvale (Sandown) (station ID 086369) (henceforth called Sandown station) is selected for the hydraulic modelling as this station is located closest to the Calibration Area (at a distance of $2 \mathrm{kms}$ ), as shown in Figure 1 (b). The rainfall data available from the Sandown station is at a daily time step. Rainfall data from another station, the Moorabbin Airport station (BoM station ID 086077) (also identified in Figure 1 (b)) is available at a time step of one minute, which is used later for disaggregation and hydraulic computations. The correlation of the daily recorded rainfall from July 2012 to January 2013 these two stations is 0.6576 . 
Molavi et al., Implementing future climate change scenarios using a stormwater drainage model for an urban catchment in Melbourne

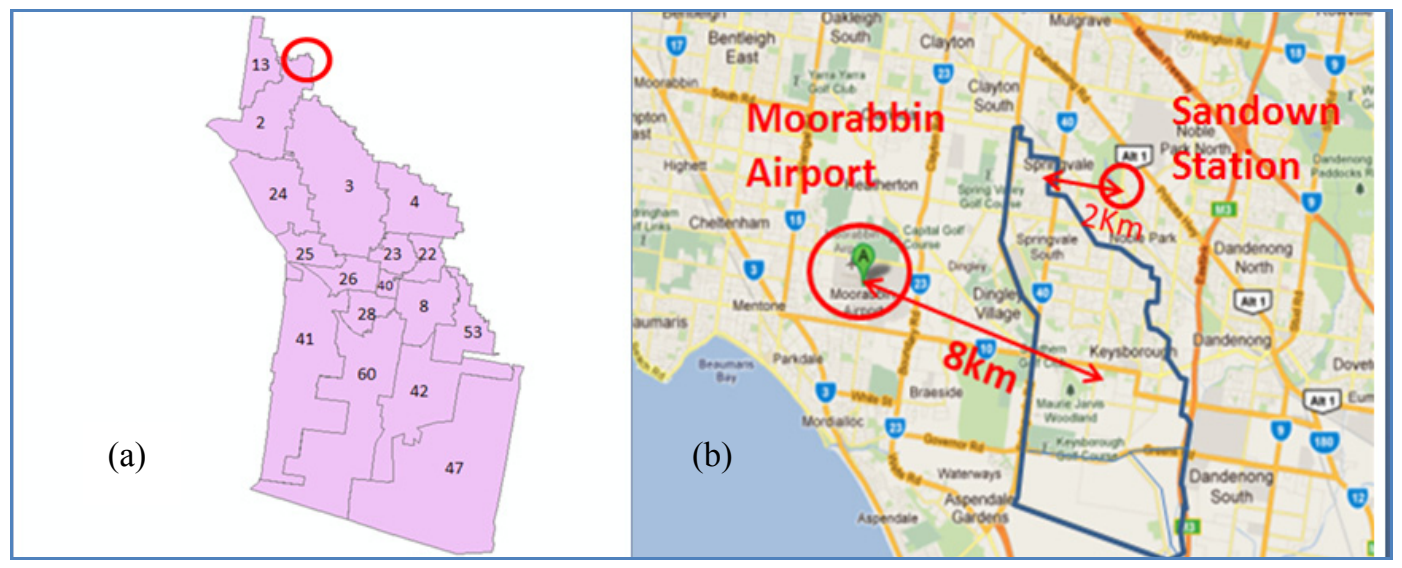

Figure 1. (a) The Springvale case study site and the Calibration Area located in the northeast of the site (denoted by red circle) and (b) Moorabbin Airport and Sandown rain gauge stations

\section{HYDRAULIC MODEL}

\subsection{Model Setup}

A hydraulic model was built using GIS data for the drainage system of the City of the Greater Dandenong for the whole of Springvale urban catchment. The US EPA's freely available SWMM 5 (Rossman, 2010) software is used for the hydraulic modelling. SWMM 5 is a 1D model and is not able to model the flow spreading across the surface (i.e. in 2D), but is able to save the water off the pits during an overflow and return them to the system later when the level of the water recedes. Data in text format that is exported from GIS is imported into SWMM 5.

One of the crucial tasks in setting up the model was to assign the correct effective area producing the surface runoff volume to each node (also known as inlet pit receiving the surface runoff). It is important to allocate the effective area for each node as accurately as possible. In order to accomplish this crucial task, the Thiessen-polygon approach, which has been extensively used to address rainfall variation, is adopted in this study. This approach is implemented using the Thiessen-polygon tool available in ESRI's ArcGIS software. Thiessen-polygons are constructed around each effective node (inlet pit) based on the adjacent nodes that share the area. The allocated area is divided by scaling the distance of the nodes from each other and consequently each polygon contains only one input point. Only open pits were considered to produce the Thiessen polygon layer. This layer generated by ArcGIS holds all needed information to be used in SWMM, such as the area for the catchment associated with the pits, etc. The hydraulic characteristics of the catchments (for example, the Manning's coefficient, percentage of impervious area, etc) were added later through the SWMM user interface.

The hydraulic model for two catchments (number 2 and 13) is shown in Figure 2(a) and the hydraulic model for the Calibration Area is presented in Figure 2 (b). In this study, only the model for the Calibration Area is calibrated (as flow data is available at the outlet of the Calibration Area) and the estimated parameters are then extended across the complete catchment. Model calibration is discussed in the next sub-section.

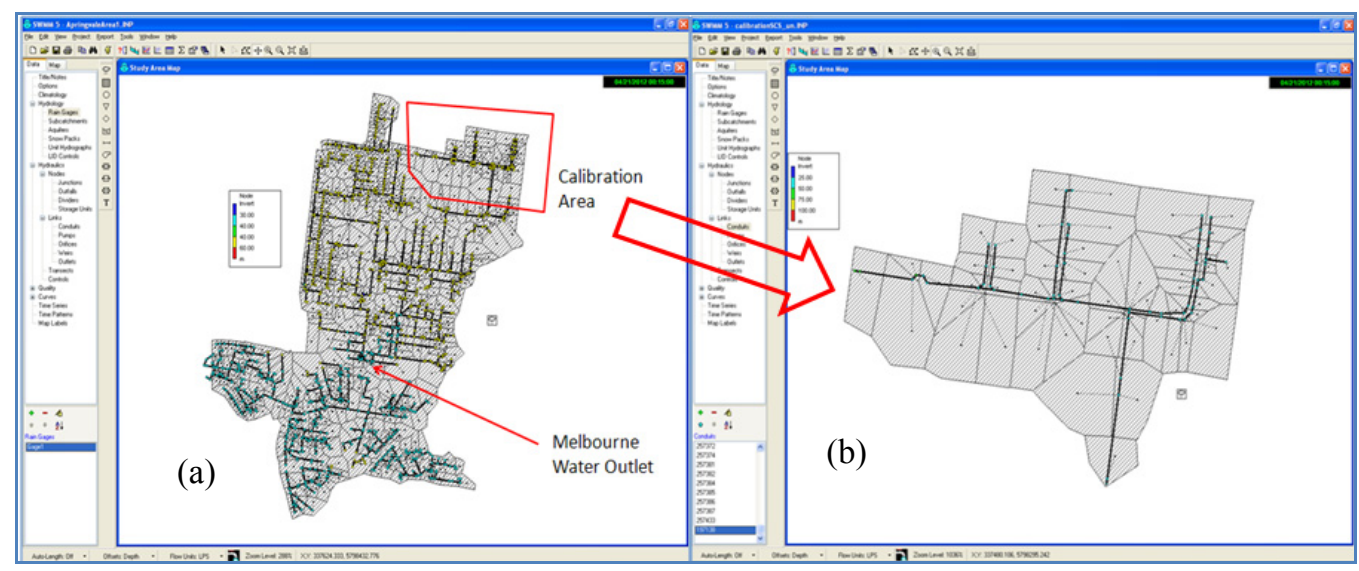

Figure 2. (a) The drainage model for the combined catchments 2 and 13 and (b) The drainage model for the Calibration Area 
Molavi et al., Implementing future climate change scenarios using a stormwater drainage model for an urban catchment in Melbourne

\subsection{Model Calibration}

The largest events in the two subsequent months (after the installation of the flowmeter), namely July and August 2012 at the Sandown station are selected for the calibration and validation of the model. The daily rainfalls at the Sandown station for the selected dates were disaggregated into minutes using the pattern of rainfall from Moorabbin airport for the same date. The model parameters were calibrated manually and a plausible range for the effective hydraulic parameters was applied and changed manually so that the computed flow peak would be as close as possible to the observed flow peak recorded by the flowmeter.

Table 1 presents the calibrated parameters for the hydraulic model. In Table 1, the percentage of the imperviousness represents the percentage of impervious area such as asphalts and building roofs that directly contribute to the runoff production. The $N$ for the impervious and pervious areas are the Manning roughness coefficients. This value is used to calculate the time of the concentration over the catchment. The parameter D-store is the depression height in mm which would be deducted from the corresponding volume of rainfall trapped on the surface and would not contribute to the runoff. The percentage of zero imperviousness is the part of the impervious area which fully contributes in runoff. Curve number is part of the SCS methodology (SCS Urban Hydrology for Small Watersheds, 1986), which is used for calculation of the runoff, peak and time of the runoff for each catchment. In this methodology, the catchments are assigned the curve

Table 1. The calibrated parameters in SWMM

\begin{tabular}{|l|l|}
\hline Parameter & Value \\
\hline$\%$ Impervious area & 15 \\
\hline$N$-Pervious & 0.1 \\
\hline$N$-Impervious & 0.01 \\
\hline D-store (Pervious) & 2.54 \\
\hline D-store (Impervious) & 1.27 \\
\hline$\%$ Zero-Imperviousness & 25 \\
\hline Curve number & 83 \\
\hline$N$-Pipe & 0.013 \\
\hline$\%$ Slope & 1.7 \\
\hline Width (m) & 50 \\
\hline ERR Routing \% & 0.11 \\
\hline ERR Runoff \% & -0.26 \\
\hline
\end{tabular}
number (CN in Equation (1)) based on their land use, hydrologic soil type and antecedent moisture. The curve number is used to calculate the potential maximum retention of the catchment ( $\mathrm{S}$ in Equation (1)), which is to be deducted from the total rainfall ( $\mathrm{P}$ in Equation (2)). The excess rainfall is calculated using equation (2) and then applied to the unit SCS hydrographs to estimate the peak volume of the runoff and the time to peak.

$$
\begin{aligned}
& S=\frac{1000}{C N}-10 \\
& P_{\theta}=\frac{(P-0.2 S)^{2}}{P+0.8 S}
\end{aligned}
$$

The parameter $\mathrm{N}$-Pipe is the Manning coefficient for the pipes, which is used in the routing calculations. The Manning coefficient for all pipes is assumed to be equal and the effects of aging of the material are not considered. The value used is a logical value for the middle aged concrete and plastic pipes (ASCE, 1982). Err is the percentage error for Runoff and Routing in the SWMM calculations. The parameters in Table 1 were implemented for the complete catchment.

Figure 3 (a) presents a comparison of the computed and observed flow hydrographs for the calibration period. The observed value of peak runoff was $118.73 \mathrm{~L} / \mathrm{sec}$ whereas the calculated value was $127.156 \mathrm{~L} / \mathrm{s}$. After the model was calibrated, the validation was conducted using the most severe event in August 2012. The total volume of rainfall for the validation date was $12.8 \mathrm{~mm}$. Using the same hydraulic parameters identified during the calibration were used in the validation and the comparison of observed and computed hydrographs is presented in Figure 3 (b). Due to the manual procedure of calibration and especially due to the fact that only peak flows were matched for the calibration, a good match between the observed and computed hydrographs for both calibration and validation periods were not possible (except the matching peak flows). As a future extension of this study, an automatic calibration of the model would be undertaken using different objective functions and for different rainfall events in wet and dry seasons. 
Molavi et al., Implementing future climate change scenarios using a stormwater drainage model for an urban catchment in Melbourne

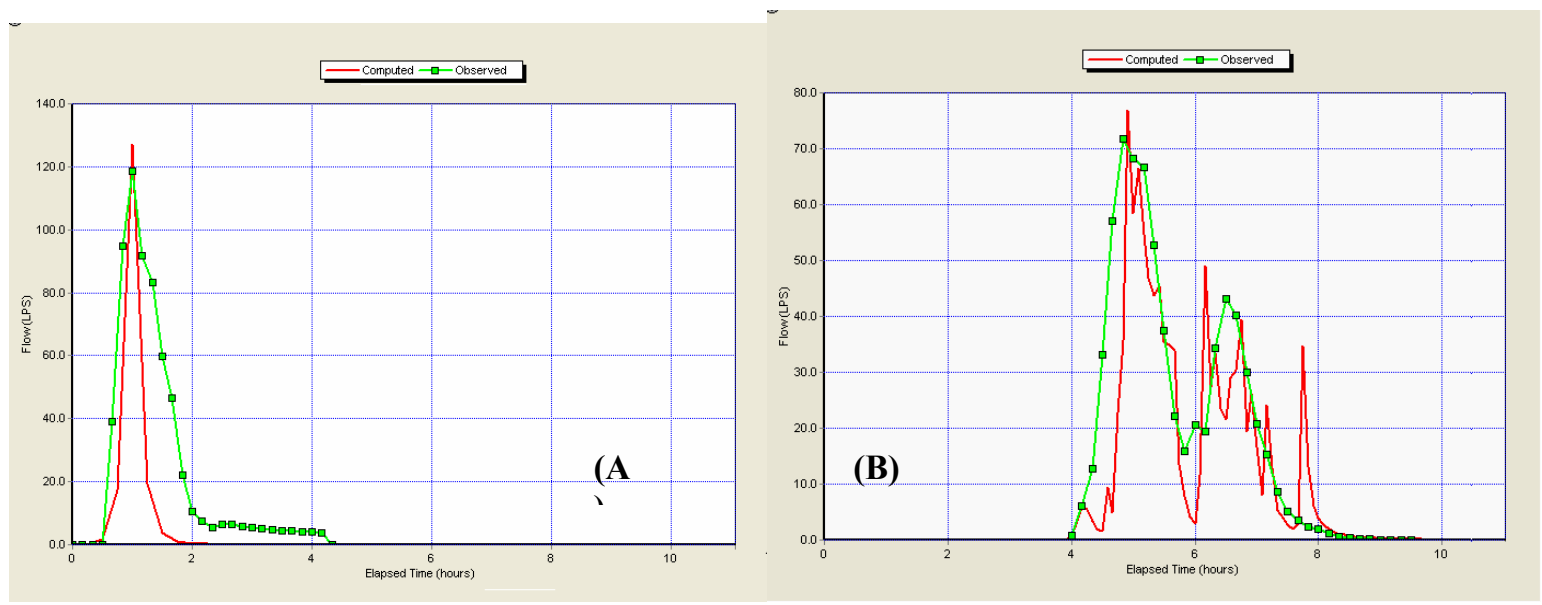

Figure 3. Comparison of observed and computed hydrographs for (a) the calibration and (b) validation periods

\section{CLIMATE CHANGE SCENARIOS}

Abbs et al. (2006) and Green and Johnson (2012) showed the the change for the top 10 events with 40 years return period with 24 and 72 hrs duration would be -20 to $40 \%$ (2030) and -40 to $70 \%$ (2070) for Victoria and lower Murray Darling Basin. Based on the study by Melbourne Water and CSIRO (2005) and Green and Johnson (2012), the impacts of 5, 10 and 20\% increase in rainfall events should be considered in the evaluations. Based on this report, the average warming would range from $0.5^{\circ} \mathrm{C}$ by 2020 to $1.4^{\circ} \mathrm{C}$ by 2050 and would result in the increase of rainfall by $10 \%$ by 2020 and $28 \%$ by 2050 . A case study on the City of Port Philip (NATCLIM, 2007 and Green and Johnson (2012)) suggest an increase in rainfall of 5\% by 2020, $35 \%$ by 2050 and $70 \%$ by 2100 for the 20 year ARI events. Molavi et al. (2011) projected rainfall to increase by $5 \%$ in average during May and August using Global Climate Models for a case study in Melbourne.

A sensitivity analysis of the hydraulic model for increasing the current IFDs by $10 \%, 20 \%$ and $30 \%$ (for the events with 1 in 40 Annual Exceedance Probability) is suggested for studies undertaking capability evaluation of the existing hydraulic structures against climate change (Green and Johnson, 2012). In this study, the $6 \mathrm{hrs}$ duration events having 50 and 100 years return period rainfall is extracted from the IFD curve for Sandown rainfall station, which is presented in Figure 4 (Bureau of Meteorology, 2013). The 6hrs event was selected in this study as the base line for the methodology of implementation of climate change scenarios. The factors of $10 \%, 20 \%$ and $30 \%$ were then applied to the hyetographs of 50 and 100 years return periods. The hyetograph pattern was produced using the coefficients available in ARR89 (Pilgrim et al., 1998).

\section{RESULTS}

Table 2 presents the results of the hydraulic model assessments for the climate change scenarios presented in the earlier section. For the event having 50 years return period and a $30 \%$ increase in the volume of rainfall, the infiltration would increase by $9.6 \%$ while the surface

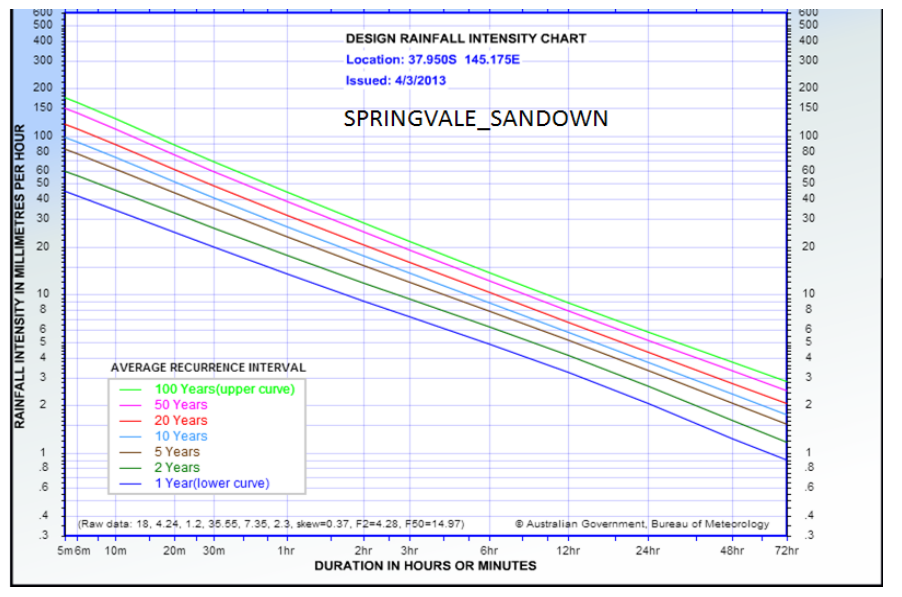

Figure 4. The IFD Curves from BoM for Sandown Station runoff would increase by around $44.5 \%$. The increase in final surface storage is relatively less than the other two factors, with an increase of about $7 \%$. For the 100 years return period and increase in rainfall by $30 \%$, the three factors namely infiltration loss, surface runoff and final surface storage increase by about $8.7 \%$, $42.8 \%$ and $7.2 \%$ respectively. 
Molavi et al., Implementing future climate change scenarios using a stormwater drainage model for an urban catchment in Melbourne

Table 2. Results for the 6hrs design rainfall and the generated scenarios

\begin{tabular}{|l|c|c|c|c|c|c|c|c|}
\hline \multirow{2}{*}{} & \multicolumn{4}{|c|}{ 6HRS_50YEARS } & \multicolumn{4}{c|}{ 6HRS_100YEARS } \\
\cline { 2 - 10 } & $+0 \%$ & $+10 \%$ & $+20 \%$ & $+30 \%$ & $+0 \%$ & $+10 \%$ & $+20 \%$ & $+30 \%$ \\
\hline Total Precipitations (mm) & 73.20 & 80.51 & 87.83 & 95.40 & 82.20 & 90.42 & 98.64 & 106.86 \\
\hline Infiltration Loss (mm) & 27.98 & 28.97 & 29.86 & 30.66 & 29.19 & 30.14 & 30.99 & 31.74 \\
\hline Surface Runoff (mm) & 43.62 & 49.91 & 56.31 & 63.03 & 51.37 & 58.59 & 65.93 & 73.37 \\
\hline Final Surface Storage (mm) & 1.62 & 1.66 & 1.70 & 1.74 & 1.67 & 1.71 & 1.75 & 1.79 \\
\hline
\end{tabular}

The results of the hydraulic analysis presented above indicate that the increase in the surface runoff is considerably higher than the increase in infiltration and storage capacity. The landuse chracteristics and hydrologic parameters of the urban catchment may be the cause for relatively lessser increase in the loss and storage capacities.

\section{DISCUSSION AND CONCLUSIONS}

In this study, a hydraulic model was built for the case study site and different scenarios of future climate change were implemented to assess its impact on the urban drainage system. The climate change scenarios used 6hrs duration design rainfalls with 50 and 100 year return periods, and scenarios with increasing rainfall values by $10 \%, 20 \%$ and $30 \%$ for each of these. It was observed that the surface runoff would increase at a higher ratio than the other two factors of infiltration loss and final surface storage. Any further increase in the extreme events would contribute in more surface runoff accumulation.

The analysis presented in this study evaluated the urban drainage system using a simple scenario. The analysis would be extended further in the future by using more scenarios based on the climatologic, hydrologic and hydraulic factors. Tran et al. (2011) presented some of the potential future scenarios namely, changes in imperviousness, changes in downstream water level, changes in drainage conditions and changes in stormwater harvesting and detention volumes that can be applied.

Other than a wider range of climate change scenarios, an automatic calibration of the hydraulic model is another useful improvement that would be undertaken as future extension of this study.

\section{ACKNOWLEDGMENTS}

The authors herewith appreciate and acknowledge the efforts and support of the authorities of City of Greater Dandenong, especially Mr. Martin Wong and his team for installing the flowmeter and collection of the recorded flow data.

\section{REFERENCES}

Abbs, D., S. Aryal, E. Campbell, J. McGregor, K. Nguyen, M. Palmer, T. Rafter, I. Watterson and B.Bates (2006). Projections of Extreme Rainfall and Cyclones. Final Report to the Australian Greenhouse Office: 111.

Arisz H, Burrell, B. C. (2006). Urban drainage infrastructure planning and design considering climate change. Proceedings of EIC Climate Change Technology Conference 2006, Engineering Institute of Canada (EIC), Ottawa Congress Center, 9-12 May, 1-9.

ASCE, (1982). Gravity Sanitary Sewer Design and Construction. ASCE Manual of Practice No. 60, New York, NY.

Bureau of Meteorology (2010). State of the climate 2010 update, viewed September 2013. http://www.csiro.au/Outcomes/Climate/Understanding/State-of-the-Climate-2010.aspx.

Bureau of Meteorology (2013). Intensity-Frequency-Duration Design Rainfalls, viewed September 2013. http://www.bom.gov.au/water/designRainfalls/ifd/index.shtml.

Green, J. and Johnson, F. (2012). Incorporation of Climate Change in Intensity-Frequency-Duration(IFD) Design Rainfall Estimates. Proceedings of the $2^{\text {nd }}$ Practical Responses to Climate Change Conference, 'Water and Climate: Policy Implementation Challenges', 1-3 May 2012, Canberra, Australia. 
Molavi et al., Implementing future climate change scenarios using a stormwater drainage model for an urban catchment in Melbourne

Grum, J., H., Jorgensen, M., Johansen, A., T., Linde, R.M., (2006). The effect of climate change on urban drainage: An evaluation based on regional climate model simulations. Water Science \& Technology 54(67), 9-17.

IPCC (Intergovernmental Panel on Climate Change), (2007). The Physical science basis. Contribution of working group I to the fourth assessment report of the intergovernmental panel on climate change. Cambridge University Press, Cambridge, United Kingdom and New York, USA, 996 pp.

Mailhot, A., Duchesne, S., (2010). Design criteria of urban drainage infrastructures under climate change. Journal of Water Resources Planning and Management, 136, 201-208.

Melbourne Water and CSIRO Urban Water and Climate Impacts Groups (2005). Melbourne WaterClimate Change Study. Implications of Potential Climate Change for Melbourne's Water Resources.

Molavi, S., Muttil, N., Tran, D., (2011). Urban flood modelling and climate change: A Melbourne area case study. MODSIM 2011, $19^{\text {th }}$ International Congress on Modelling and Simulation, Perth, Australia, 12-16 December 2011 (CD), pp. 3608 - 3614.

NATCLIM (2007). Planning for Climate Change, a case study. City of Port Phillip. Kew, Victoria.

Nie, L., Linholm, O., Lindholm, G., Syversen, E., (2009). Impacts of climate change on urban drainage systems- a case study in Fredrikstad, Norway. Urban Water Journal, 6(4), 323-332.

Pilgrim, D. H. Editor in Chief, (1998). Australian Rainfall Runoff . Institution of Engineers, Australia.

Rossman, L., A., (2010). Stormwater Management Model User's Manual Version 5.0. Water Supply and Water Resource Division. Revised July 1998, Cincinnati, Ohio USA.

Semadeni-Davies, A., Hernebring, C., Svensson, G., Gustafsson, L., (2008). The impacts of climate change and urbanization on drainage in Helsingborg, Sweden: Suburban stormwater. Journal of Hydrology, 350, $114-125$.

SCS Urban Hydrology for Small Watersheds, 2nd Ed., (TR-55), June 1986.

Tran, H., Molavi, S., and Muttil, N. (2011) Assessment framework for the impacts of climate change and urbanization on urban drainage systems. Pipelines 2011: A Sound Conduit for Sharing Solutions (C) ASCE 2011, Seattle, Washington, July 23 - 27, 2011, pp. 1403 - 1412.. 